\title{
Effects of a moderate low-carbohydrate diet on preferential abdominal fat loss and cardiovascular risk factors in patients with type 2 diabetes
}

This article was published in the following Dove Press journal:

Diabetes, Metabolic Syndrome and Obesity:Targets and Therapy 26 April 20II

Number of times this article has been viewed

\author{
Tae Sasakabe' \\ Hajime Haimoto ${ }^{2}$ \\ Hiroyuki Umegaki ${ }^{3}$ \\ Kenji Wakai ${ }^{4}$ \\ 'Department of Clinical Nutrition, \\ Haimoto Clinic, Yayoi, Kasugai, Aichi, \\ Japan; ${ }^{2}$ Department of Internal \\ Medicine, Haimoto Clinic, Yayoi, \\ Kasugai, Aichi, Japan; ${ }^{3}$ Department \\ of Geriatrics, Nagoya University \\ Graduate School of Medicine, \\ Tsurumai, Showa, Nagoya, Aichi, Japan; \\ ${ }^{4}$ Department of Preventive Medicine, \\ Nagoya University Graduate School \\ of Medicine, Tsurumai, Showa, Nagoya, \\ Aichi, Japan
}

Background: Reports have shown that visceral adipose tissue (VAT) is more closely linked to cardiovascular risk factors (CRFs) than subcutaneous adipose tissue (SAT). We aimed to elucidate preferential abdominal fat loss and the correlations between abdominal fat reductions and changes in CRFs achieved with a moderate low-carbohydrate diet (LCD) in patients with type 2 diabetes (T2DM).

Patients and methods: Fifty-two outpatients (28 men and 24 women, mean age \pm SD: $60.0 \pm 10.5$ years) with hemoglobin $\mathrm{A}_{1 \mathrm{c}}\left(\mathrm{HbA}_{1 \mathrm{c}}\right)$ levels $\geq 6.5 \%$ were on an LCD for 6 months. Over a 6-month period, we measured their abdominal fat distribution (using $\mathrm{CT}$ ) and assessed CRFs, including body mass index (BMI), $\mathrm{HbA}_{1 \mathrm{c}}$, fasting blood glucose (FBG), serum insulin, high-density lipoprotein cholesterol (HDL-C), low-density lipoprotein cholesterol (LDL-C), and triglyceride levels.

Results: The patients showed good compliance with the LCD (1812 $\pm 375 \mathrm{kcal} / \mathrm{day}$, \% carbohydrate:fat:protein $=35: 40: 19$ for men; $1706 \pm 323 \mathrm{kcal} /$ day, \% carbohydrate:fat:protein = 41:36:21 for women). Significant decreases $(P=0.05)$ in $\mathrm{BMI}$ and $\mathrm{HbA}_{1 \mathrm{c}}$ levels were observed, along with an increase in HDL-C $(P=0.021)$ in men and a decrease in LDL-C $(P=0.001)$ in women. VAT $\left(-21.6 \mathrm{~cm}^{2}, P<0.001\right.$ in men; $-19.6 \mathrm{~cm}^{2}, P<0.001$ in women) and SAT $\left(-13.5 \mathrm{~cm}^{2}, P=0.004\right.$ in men; $-19.1 \mathrm{~cm}^{2}, P=0.003$ in women $)$ significantly decreased. The loss of VAT $(\% \Delta$ VAT $)$ was greater than that of SAT $(\% \Delta \mathrm{SAT})$ in women $(P=0.022)$. A similar but not significant predominance of VAT loss was detected in men $(P=0.111)$. In women, the $\% \Delta$ SAT significantly correlated with changes in FBG $(\Delta \mathrm{FBG})(r=0.417)$ and HDL-C $(\Delta \mathrm{HDL})$ $(r=-0.720)$, as was $\% \Delta$ VAT with changes in triglyceride $(\Delta \mathrm{TG})(r=0.591)$.

Conclusion: Six months of a moderate LCD resulted in preferential VAT loss only in women, with significant correlations between $\% \Delta \mathrm{SAT}$ and both $\triangle \mathrm{HDL}$ and $\triangle \mathrm{FBG}$, as well as between $\% \Delta$ VAT and $\triangle \mathrm{TG}$. Our results suggest that an LCD has the potential to reduce abdominal fat in patients with T2DM and deterioration of serum lipid profiles.

Keywords: low-carbohydrate diet, visceral adipose tissue, subcutaneous adipose tissue, cardiovascular risk factors

\section{Introduction}

Low-carbohydrate diets (LCDs) have attracted interest for weight loss, glycemic control, and the management of cardiovascular risk factors in overweight patients with type 2 diabetes (T2DM). ${ }^{1,2}$ Among their reported advantages over high-carbohydrate diets (HCDs) are improvements in both serum high-density lipoprotein cholesterol (HDL-cholesterol) levels and triglyceride levels in obese patients. ${ }^{3-5}$

The proportion of energy obtained from carbohydrates in East Asian populations is generally higher (about 60\%) and the fat percentage generally lower (about 25\%)
Correspondence:Tae Sasakabe Haimoto Clinic, I-80 Yayoi, Kasugai, Aichi 486-0838, Japan

Tel +8I 568858226

Fax +81568858315

Email haiclipar-mail78@gol.com 
compared with Western populations. ${ }^{6-9}$ Therefore, compared with HCDs, moderate (non-ketogenic) LCDs, but not strict (ketogenic) LCDs, may be sufficiently effective for glycemic control in East Asian patients with T2DM. Moreover, a moderate LCD is more acceptable to patients with T2DM because they are not required to strictly limit carbohydrates. ${ }^{10,11}$ Indeed, we demonstrated the efficacy of a moderate LCD (30\%-45\% carbohydrate diet) in glycemic control, weight loss, and improvement of serum lipid profiles in T2DM patients with a low attrition rate. ${ }^{11,12}$ Even in the Western population, strict and moderate LCDs are reported to be equally effective in controlling body weight and serum lipid profiles. ${ }^{13}$

It has been proposed that abdominal fat accumulation raises cardiovascular risk. As compared with subcutaneous adipose tissue (SAT), visceral adipose tissue (VAT) in particular is more closely linked to glucose intolerance, hypertension, dyslipidemia, and insulin resistance. ${ }^{14-16}$ Therefore, VAT is widely assumed to be a major predictor of metabolic syndrome and insulin resistance. Indeed, experimental studies have demonstrated that VAT and SAT play different physiological and biochemical roles. ${ }^{16}$ Men have significantly more VAT than women, which may explain why women have fewer cardiovascular events than men. ${ }^{17}$ Thus, if moderate LCDs result in a greater decrease in VAT than SAT, such LCDs may be useful for controlling not only blood glucose levels, but also abdominal fat.

Many intervention studies involving HCDs and either exercise or drugs have been conducted to assess changes in abdominal fat distribution in obese subjects. However, although HCDs can result in absolute VAT and SAT loss, these diets do not result in preferential abdominal fat loss. ${ }^{18}$ To date, only a few studies have examined the effects of LCDs on preferential abdominal fat loss and the associations between the loss of adipose tissue and improvement in cardiovascular risk factors in nonobese and obese patients with and without T2DM. ${ }^{19}$

Therefore, in the present study, we investigated which abdominal fat tissues (VAT or SAT) would be preferentially reduced by a 6-month moderate LCD. The subjects were non-obese patients with T2DM who were typical of those commonly treated in Japan. ${ }^{20,21}$ We also sought to determine whether decreases in VAT or SAT were associated with changes in cardiovascular risk factors (body mass index [BMI], blood pressure [BP], hemoglobin $\mathrm{A}_{1 \mathrm{c}}\left[\mathrm{HbA}_{\mathrm{lc}}\right]$ levels, fasting blood glucose [FBG], serum insulin [IRI] and serum lipid profiles).

\section{Patients and methods}

We invited all new outpatients with T2DM and $\mathrm{HbA}_{1 \mathrm{c}}$ levels of $6.5 \%$ or above to participate in a 6-month intervention study from April 2007 to November 2008 at the Haimoto Clinic. Patients with serum creatinine levels $>1.5 \mathrm{mg} / \mathrm{dL}$, severe complications from diabetes (proliferative retinopathy, symptomatic neuropathy, or a diabetic foot), ketoacidosis, soft drink ketosis, cancer, severe heart failure, and liver cirrhosis were excluded. Five patients on hormone and/or insulin treatment were also excluded due to the considerable effects of these drugs on body weight (BW) and serum insulin levels. The remaining 63 patients participated in the study.

We measured the participants' BW, BP, and $\mathrm{HbA}_{1 \mathrm{c}}$ levels every month. Levels of FBG and serum insulin, triglyceride (TG), low-density lipoprotein cholesterol (LDL-C) and HDL-C were analyzed in the fasting state at baseline and after 6 months. Changes in VAT, SAT, total adipose tissue (TAT) and waist circumference (WC) were also assessed at baseline and after 6 months by computed tomography (CT).

All participants gave informed consent, and the study protocol was approved by the Ethics Committee of the Nagoya Tokushukai General Hospital.

\section{Laboratory methods}

Plasma glucose concentrations were determined by enzymatic methods (Shino-Test Co. Kanagawa, Japan). Serum insulin levels were measured using the standard double antibody radioimmunoassay method (Fujirebio Inc. Tokyo, Japan). Enzymatic methods were used to measure TG levels (Daiichi Pure Chemicals Co., Tokyo, Japan). Direct methods were used to assay serum LDL-C and HDL-C levels (Daiichi Pure Chemicals Co., Tokyo, Japan). HbA ${ }_{1 c}$ levels were measured using high-performance liquid chromatography (Arkley Co., Kyoto, Japan).

\section{Assessment of body composition}

BW was determined using an electronic scale while patients were wearing only underwear. BMI was calculated by dividing weight in kilograms by the square of height in meters. To eliminate the effect of sex and age, we used the standard deviation score of BMI as well as crude BMI values. The score was computed using the following formula: (BMI - mean)/SD. We used the average and standard deviation of BMI by sex and 10-year age group in the National Health and Nutrition Survey, Japan, $2009^{22}$ because of the small number of participants in some age groups in the present study.

The surface areas of VAT and SAT were measured by CT (Hitachi Medical Corporation X-ray CT system Pronto Si), and 
patients were scanned at the navel. These areas and WC were measured using image analysis software (Hitachi Medical Corporation Fat Pointer, version 1.10) as described previously. ${ }^{23}$

\section{The carbohydrate-reduced diet}

The main principle of the LCD used in this study was to eliminate carbohydrate-rich foods depending on each patient's $\mathrm{HbA}_{1 \mathrm{c}}$ levels, as described previously. ${ }^{11,12}$ In brief, patients with $\mathrm{HbA}_{1 \mathrm{c}}$ levels $<9.0 \%$ were asked to eliminate carohydrate-rich foods from their dinner, whereas patients with an $\mathrm{HbA}_{1 \mathrm{c}}$ level $\geq 9.0 \%$ were asked to eliminate carbohydrates twice a day (from breakfast and dinner). It was easy for patients to stay on the LCD because no strict protein:fat:carbohydrate (PFC) ratio was prescribed, and they were permitted to eat as much protein and fat as they wanted, including saturated fat. There were no other restrictions.

A dietician (TS) gave instructions to all participants 3 times during the first month and once a month thereafter. The participants were instructed to maintain their baseline physical activity level throughout the study period. Their dietary intake was assessed after 5 months from 3-day food records and an interview with a dietitian and the data were analyzed using the HealthyMaker432 (mushroomsoft, Okayama, Japan). The participants had not previously been instructed to follow a LCD before this intervention. They were asked about changes in their physical activity levels on a questionnaire that they filled out at the end of the study.

\section{Statistical analysis}

Data are presented as mean $\pm \mathrm{SD}$. Either the paired $t$-test or its nonparametric counterpart (Wilcoxon signed rank test) was used to assess changes in all the parameters during the 6 -month period. The unpaired $t$-test was applied to assess the differences in VAT and SAT at baseline and in the percentage of dietary macronutrient intake between men and women.

We compared the ratio of VAT area to SAT area (V/S ratio) at baseline and after the 6-month period. The changes in some variables during the 6-month study period (ie, 6-month value minus baseline value) are presented as $\Delta$ variable (eg, $\Delta \mathrm{BMI}, \Delta \mathrm{SBP}, \Delta \mathrm{DBP}, \Delta \mathrm{FBG}, \Delta \mathrm{IRI}, \Delta \mathrm{HbA}_{1 \mathrm{c}}, \Delta \mathrm{TG}$, $\Delta \mathrm{LDL}-\mathrm{C}$, and $\Delta \mathrm{HDL}-\mathrm{C})$. We used $\% \Delta \mathrm{VAT}, \% \Delta \mathrm{SAT}$ and $\Delta \mathrm{V} / \mathrm{S}$ as indicators of differential changes in VAT or SAT, although various parameters have been used in previous intervention studies (eg, $\Delta \mathrm{VAT}, \Delta \mathrm{SAT}, \Delta \mathrm{VAT} / \Delta \mathrm{SAT}, \% \Delta \mathrm{VAT}$, $\% \Delta \mathrm{SAT}, \% \Delta \mathrm{VAT} / \% \Delta \mathrm{SAT}, \mathrm{V} / \mathrm{S}$, and $\Delta \mathrm{V} / \mathrm{S}) .{ }^{18,19,24-29}$ The parameters $\% \Delta$ VAT and $\% \Delta$ SAT were computed using the following formula: $100-(100 \times[$ FAT area at 6 months/FAT area at baseline]).
The correlations between abdominal fat distribution and either cardiovascular risk factors or body composition at baseline and the correlations between changes in these variables over the 6-month period were assessed with Spearman correlation coefficients. Multiple regression analyses adjusted for age were performed on the significant and strong correlations between changes in abdominal fat and cardiovascular risk factors. All statistical analyses were performed using the SPSS statistical package (version 11.0; SPSS, Inc., Chicago, IL). $P$ values less than 0.05 were considered to be statistically significant.

\section{Results \\ Baseline characteristics of patients}

Of the 63 patients enrolled in the study, 2 patients voluntarily dropped out, 2 refused the CT assessment at 6 months, 3 began to require insulin treatment, and 4 were hospitalized because of diseases other than T2DM. After excluding these patients, 52 were left for the analyses (28 men, mean age \pm SD: $57.3 \pm 10.6$ years, range: $35-73$ years and 24 women, mean age \pm SD: $63.6 \pm 9.5$ years, range: $34-82$ years). All but one of the female participants were postmenopausal.

The patients' characteristics at baseline are shown in Table 1. The mean BMI was $25.4 \pm 4.5 \mathrm{~kg} / \mathrm{m}^{2}$ for men and $23.9 \pm 3.4 \mathrm{~kg} / \mathrm{m}^{2}$ for women, and only 5 patients exceeded $30.0 \mathrm{~kg} / \mathrm{m}^{2}$. The mean standard deviation score of BMI was $0.49 \pm 1.34$ for men and $0.30 \pm 0.93$ for women

$\mathrm{HbA}_{1 \mathrm{c}}$ levels were $8.4 \% \pm 1.5 \%$ in men and $8.6 \% \pm 2.0 \%$ in women. VAT was much larger in men than in women (men: $150.9 \pm 57.5 \mathrm{~cm}^{2}$, women: $99.6 \pm 51.7 \mathrm{~cm}^{2}$ ), whereas SAT was larger in women (men: $123.4 \pm 70.7 \mathrm{~cm}^{2}$, women: $187.3 \pm 70.0 \mathrm{~cm}^{2}$ ). No changes in physical activity levels during the study period were reported in the questionnaire.

As for the correlations of VAT or SAT distribution and WC with cardiovascular risk factors in men, we found a strong positive correlation between VAT and BMI (Spearman correlation coefficient $[r]=0.669, P<0.001)$. There were also strong, positive correlations between SAT, TAT, or WC and either BMI ( $r=0.590,0.819$ or 0.806 , respectively and $P \leq 0.001$ for all) or serum insulin levels $(r=0.655,0.565$, 0.673 and $P<0.001, P=0.002, P<0.001$, respectively). Moderate inverse correlations between either SAT or WC and serum HDL-C levels $(r=-0.473,-0.472$ and $P=0.020$ or $P=0.020$, respectively) were also observed. In women, we found strong positive correlations between VAT, SAT, TAT, or WC and either BMI ( $r=0.652,0.730,0.796$, or 0.865 and $P \leq 0.001$ for all) or serum insulin levels ( $r=0.658$, $0.663,0.762$, or 0.759 and $P<0.001$ for all). A significant 
Table I Changes in abdominal fat distribution and cardiovascular risk factors during the 6-month moderate low-carbohydrate diet

\begin{tabular}{|c|c|c|c|c|c|c|}
\hline & \multicolumn{3}{|l|}{ Men $(n=28)$} & \multicolumn{3}{|c|}{ Women $(n=24)$} \\
\hline & Baseline & After 6 months & $P$ & Baseline & After 6 months & $P$ \\
\hline Body weight (kg) & $70.7 \pm 13.6$ & $68.7 \pm 12.7$ & $0.004 *$ & $55.8 \pm 7.2$ & $54.1 \pm 7.4$ & 0.002 \\
\hline Body mass index $\left(\mathrm{kg} / \mathrm{m}^{2}\right)$ & $25.4 \pm 4.5$ & $24.6 \pm 4.1$ & $0.003 *$ & $23.9 \pm 3.4$ & $23.2 \pm 3.4$ & 0.002 \\
\hline Standard deviation score of body mass index & $0.49 \pm 1.34$ & $0.26 \pm 1.24$ & $0.004 *$ & $0.30 \pm 0.93$ & $0.08 \pm 0.93$ & 0.002 \\
\hline Systolic blood pressure $(\mathrm{mmHg})$ & $132 \pm 23$ & $133 \pm 16$ & 0.864 & $143 \pm 22$ & $134 \pm 19$ & 0.142 \\
\hline Diastolic blood pressure $(\mathrm{mmHg})$ & $81 \pm 15$ & $78 \pm 9$ & 0.813 & $80 \pm 13$ & $78 \pm 9.6$ & 0.460 \\
\hline Hemoglobin $A_{I c}(\%)$ & $8.4 \pm 1.5$ & $6.5 \pm 0.6$ & 0.000 & $8.6 \pm 2.0$ & $7.0 \pm 1.0$ & $0.000 *$ \\
\hline Fasting blood glucose (mg/dL) & $157 \pm 47$ & $136 \pm 29$ & 0.024 & $164 \pm 50$ & $144 \pm 33$ & 0.059 \\
\hline Fasting serum insulin $(\mu \mathrm{IU} / \mathrm{mL})$ & $9.11 \pm 9.11$ & $8.18 \pm 5.15$ & $0.467^{*}$ & $6.63 \pm 3.6 I$ & $6.87 \pm 3.81$ & $0.634^{*}$ \\
\hline Serum triglyceride $(\mathrm{mg} / \mathrm{dL})$ & $126 \pm 120$ & $110 \pm 77$ & $0.36 I^{*}$ & $112 \pm 63$ & $105 \pm 59$ & $0.468^{*}$ \\
\hline Serum LDL cholesterol (mg/dL) & $134 \pm 39$ & $125 \pm 29$ & $0.076^{*}$ & $157 \pm 35$ & $133 \pm 28$ & $0.001 *$ \\
\hline Serum HDL cholesterol $(\mathrm{mg} / \mathrm{dL})$ & $47 \pm 13$ & $52 \pm 14$ & $0.021 *$ & $59 \pm 14$ & $60 \pm 16$ & 0.319 \\
\hline $\operatorname{VAT}\left(\mathrm{cm}^{2}\right)$ & $150.9 \pm 57.5$ & $129.4 \pm 57.8$ & 0.000 & $99.6 \pm 51.7$ & $80.0 \pm 40.7$ & $0.000 *$ \\
\hline$\Delta \mathrm{VAT}\left(\mathrm{cm}^{2}\right)$ & & $-21.6 \pm 26.2$ & & & $-19.6 \pm 19.5$ & \\
\hline$\% \triangle V A T$ & & $-14.2 \pm 21.6$ & & & $-18.9 \pm 19.0$ & \\
\hline SAT $\left(\mathrm{cm}^{2}\right)$ & $123.4 \pm 70.7$ & $109.9 \pm 63.8$ & 0.004 & $187.3 \pm 70.0$ & $168.1 \pm 67.3$ & $0.003^{*}$ \\
\hline$\Delta \mathrm{SAT}\left(\mathrm{cm}^{2}\right)$ & & $-13.5 \pm 22.8$ & & & $-19.1 \pm 29.9$ & \\
\hline$\% \triangle S A T$ & & $-9.0 \pm 23.1$ & & & $-8.8 \pm 17.9$ & \\
\hline TAT $\left(\mathrm{cm}^{2}\right)$ & $274.4 \pm 106.4$ & $239.3 \pm 103.6$ & 0.000 & $286.9 \pm 103.5$ & $248.1 \pm 94.6$ & 0.000 \\
\hline$\Delta \mathrm{TAT}\left(\mathrm{cm}^{2}\right)$ & & $-35.1 \pm 42.1$ & & & $-38.8 \pm 36.0$ & \\
\hline$\% \Delta T A T$ & & $-12.8 \pm 19.3$ & & & $-13.4 \pm 15.2$ & \\
\hline $\mathrm{V} / \mathrm{S}$ ratio & $1.40 \pm 0.67$ & $1.30 \pm 0.58$ & $0.069 *$ & $0.57 \pm 0.30$ & $0.49 \pm 0.21$ & $0.013^{*}$ \\
\hline Waist circumference $(\mathrm{cm})$ & $88.9 \pm 10.1$ & $86.3 \pm 10.2$ & 0.000 & $87.0 \pm 8.8$ & $84.6 \pm 9.0$ & 0.002 \\
\hline
\end{tabular}

Notes: Values are means \pm SD. Patients receiving lipid-lowering drugs ( 4 men and 5 women) were excluded from the analysis of lipid profiles, as were patients receiving antihypertensive drugs (II men and 10 women) from the analysis of blood pressure; *Nonparametric counterpart (Wilcoxon signed rank test). Abbreviations: VAT, visceral adipose tissue; SAT, subcutaneous adipose tissue; TAT, total adipose tissue; V/S ratio, ratio of visceral adipose tissue area to subcutaneous adipose tissue area.

inverse correlation between VAT and serum HDL-C levels ( $r=0.567$ and $P=0.011$ ) was also observed. Applying the standard deviation score of BMI did not materially change the correlations of VAT, SAT, TAT, or WC with BMI in both sexes $(P \leq 0.001$ for all $)$.

\section{Assessment of dietary intake}

Total energy intake, assessed by 3-day food records, was $1812 \pm 375 \mathrm{kcal} /$ day for men and $1706 \pm 323 \mathrm{kcal} /$ day for women. The average daily percentages of intake for carbohydrates, fat, and protein ( $\%$ energy) were $34.5 \% \pm 8.0 \%$, $39.6 \% \pm 9.0 \%$, and $19.1 \% \pm 3.4 \%$ for men and $40.6 \% \pm 8.1 \%$, $36.4 \% \pm 7.4 \%$, and $20.5 \% \pm 2.4 \%$ for women, respectively (Table 2$)$. The carbohydrate intake ( $\%$ energy) was significantly higher in women than in men $(P=0.010)$.

\section{Changes in anthropometric variables, cardiovascular risk factors, and antidiabetic drug use over 6 months}

In men, the mean BMI $\left(-0.7 \pm 1.2 \mathrm{~kg} / \mathrm{m}^{2}\right)$, the standard deviation score of $\mathrm{BMI}(-0.23 \pm 0.37), \mathrm{HbA}_{1 \mathrm{c}}(-1.8 \% \pm 1.4 \%)$ and FBG $(-20 \pm 42 \mathrm{mg} / \mathrm{dL})$ were significantly decreased, and serum
HDL-C (4.5 $\pm 8.8 \mathrm{mg} / \mathrm{dL})$ levels were significantly increased after 6 months. However, no significant changes were observed in the serum LDL-C and TG levels (Table 1). In women, however, the mean BMI $\left(-0.8 \pm 1.0 \mathrm{~kg} / \mathrm{m}^{2}\right)$, the standard deviation score of BMI $(-0.22 \pm 0.30), \mathrm{HbA}_{1 \mathrm{c}}(-1.7 \% \pm 1.6 \%)$ and LDL-C levels $(-24 \pm 27 \mathrm{mg} / \mathrm{dL})$ were significantly decreased, whereas the mean serum TG and HDL-C levels were not significantly altered after 6 months (Table 1).

Sixteen of the patients had already been prescribed antidiabetic drugs by other physicians before initiation of the study. The number of patients (n) who took sulfonylureas decreased and some of the remaining patients' doses were lowered over the 6 months (glibenclamide: $\mathrm{n}$; from 5 to 1 , mean dose; from 5 to $2.5 \mathrm{mg}$ /day; glimepiride: $\mathrm{n}$; from 6 to 7 , mean dose; from 2.8 to $1.5 \mathrm{mg} /$ day; gliclazide: $\mathrm{n}$; from 1 to 1 , mean dose; from 80 to $20 \mathrm{mg}$ /day). As for other antidiabetic drugs, the number of patients (n) who received nateglinide, mitiglinide, voglibose, and pioglitazone also decreased (nateglinide: $n$; from 1 to 0 , mitiglinide: $n$; from 1 to 0 , pioglitazone: $n$; from 4 to 1 , voglibose: $n$; from 8 to 3 ). The number of patients who took metformin slightly increased (from 5 to 7 ), although the mean dose decreased from 600 to $500 \mathrm{mg} /$ day. 
Table 2 Daily dietary intake at 5 months after baseline

\begin{tabular}{|c|c|c|}
\hline & Men $(n=28)$ & Women $(n=24)$ \\
\hline Total energy intake (kcal) & $1812 \pm 375$ & $1706 \pm 323$ \\
\hline Carbohydrate (g) & $153.8 \pm 37.7$ & $171.8 \pm 40.5$ \\
\hline Soluble fiber (g) & $2.7 \pm 1.0$ & $3.1 \pm 1.0$ \\
\hline Insoluble fiber (g) & $10.1 \pm 3.7$ & $10.6 \pm 4.0$ \\
\hline Carbohydrate (\% energy) & $34.5 \pm 8.0$ & $40.6 \pm 8.1$ \\
\hline Fat $(g)$ & $79.4 \pm 24.3$ & $69.6 \pm 21.7$ \\
\hline Saturated fat (g) & $21.7 \pm 7.2$ & $17.4 \pm 6.8$ \\
\hline Monounsaturated fat $(\mathrm{g})$ & $32.7 \pm I I .1$ & $27.7 \pm 10.0$ \\
\hline Polyunsaturated fat (g) & $15.5 \pm 5.6$ & $15.8 \pm 5.7$ \\
\hline Fat (\% energy) & $39.6 \pm 9.0$ & $36.4 \pm 7.4$ \\
\hline Protein $(\mathrm{g})$ & $85.4 \pm 19.7$ & $86.8 \pm 15.4$ \\
\hline Protein (\% energy) & $19.1 \pm 3.4$ & $20.5 \pm 2.4$ \\
\hline \multicolumn{3}{|l|}{ Foods rich in carbohydrate } \\
\hline Rice (g) & $166 \pm 85$ & $160 \pm 57$ \\
\hline Noodles (g) & $4 I \pm 46$ & $57 \pm 61$ \\
\hline Bread (g) & $24 \pm 35$ & $19 \pm 29$ \\
\hline Potatoes (g) & $18 \pm 34$ & $22 \pm 46$ \\
\hline Fruit (g) & $34 \pm 73$ & $64 \pm 78$ \\
\hline Confectioneries (g) & $17 \pm 24$ & $19 \pm 16$ \\
\hline Sugar (g) & $7 \pm 7$ & $8 \pm 7$ \\
\hline
\end{tabular}

Note: values are means \pm SD.

\section{Changes in abdominal fat distribution}

The parameters $\triangle \mathrm{VAT}, \triangle \mathrm{SAT}$, and $\mathrm{WC}$ were significantly decreased in both men and women during the 6-month period $(P<0.05$ for all, Table 1$)$.

In men, despite an absolute decrease in VAT $\left(-21.6 \pm 26.2 \mathrm{~cm}^{2}\right), \% \Delta$ VAT $(-14.2 \% \pm 21.6 \%)$ was not significantly different from $\% \Delta$ SAT $(-9.0 \% \pm 23.1 \%)$ $(P=0.111)$. However, a significant decrease in $\mathrm{V} / \mathrm{S}$ $(P=0.069)$ was not observed (Table 1$)$. In women, along with an absolute decrease in VAT $\left(-19.6 \pm 19.5 \mathrm{~cm}^{2}\right), \% \Delta$ VAT $(-18.9 \% \pm 19.0 \%)$ was significantly higher than $\% \Delta$ SAT $(-8.8 \% \pm 17.9 \%)(P=0.022)$, and $\mathrm{V} / \mathrm{S}$ was also significantly decreased $(P=0.013)$.

\section{Associations between changes in abdominal fat distribution and cardiovascular risk factors}

In men, no significant correlations were observed between changes in abdominal adipose tissue distribution ( $\triangle \mathrm{VAT}$, $\Delta \mathrm{SAT}, \Delta \mathrm{TAT}, \% \Delta \mathrm{VAT}, \% \Delta \mathrm{SAT}$, and $\% \Delta \mathrm{TAT}$ ) and changes in cardiovascular risk factors (Table 3). Meanwhile, $\Delta \mathrm{TAT}$, $\% \Delta \mathrm{SAT}$, and $\% \Delta \mathrm{TAT}$ were strongly correlated with $\Delta \mathrm{FBG}$ in women ( $r=0.533$ for $\Delta \mathrm{TAT}, r=0.417$ for $\% \Delta \mathrm{SAT}$, and $r=0.461$ for $\% \Delta$ TAT, Table 3). Similarly, $\Delta$ SAT, $\Delta$ TAT, $\% \Delta \mathrm{SAT}$, and $\% \Delta \mathrm{TAT}$ were all strongly and inversely correlated with $\Delta$ HDL-C in women $(r=-0.699$ for $\Delta$ SAT, $r=-0.567$ for $\Delta \mathrm{TAT}, r=-0.720$ for $\% \Delta \mathrm{SAT}$, and $r=-0.554$ for $\% \Delta \mathrm{TAT}$, Table 3$)$. In addition, a significant inverse correlation between $\Delta \mathrm{WC}$ and $\Delta \mathrm{HDL}-\mathrm{C}$ was detected $(r=-0.622)$, as was a similar correlation between either $\triangle \mathrm{SAT}$ or $\Delta \mathrm{WC}$ and $\Delta \mathrm{SBP}(r=-0.543$ for $\Delta \mathrm{SAT}$ and $r=-0.550$ for $\Delta \mathrm{WC}$, Table 3$)$. In contrast, only $\% \Delta$ VAT significantly correlated with $\Delta \mathrm{TG}(r=0.591$, Table 3$)$.

In multiple regression analyses that were adjusted for age, the following associations remained significant in women: between $\% \Delta$ VAT and $\Delta \mathrm{TG}(P=0.005)$, between $\triangle \mathrm{SAT}$ and $\triangle$ HDL-C $(P<0.001)$, between $\% \Delta$ SAT and $\triangle$ HDL-C $(P<0.001)$, and between $\triangle \mathrm{WC}$ and $\Delta$ HDL-C $(P<0.001)$. When five patients who had received pioglitazone, which influences abdominal fat distribution and serum lipid profiles, were excluded, the strong correlations observed in women were not materially altered (data not shown).

\section{Discussion}

This study is the first to show that, in outpatients with T2DM, a significant decrease in both VAT and SAT in men and women with good glycemic and BMI control, as well as a tapering off of sulfonylurea use and an improvement in serum lipid profiles, can be achieved with a moderate LCD (about a 38\% carbohydrate diet). Significant preferential VAT loss was achieved in women. VAT loss was greater than SAT loss in men as well, but the difference did not reach statistical significance. At the same time, significant correlations of $\% \Delta \mathrm{SAT}$ with $\Delta \mathrm{FBG}$ and $\Delta \mathrm{HDL}-\mathrm{C}$ and significant correlations of $\% \Delta$ VAT with $\Delta \mathrm{TG}$ were observed only in women.

\section{Limitations}

First, the use of antidiabetic drugs (especially pioglitazone) that influence SAT and HDL-C may have affected the results. ${ }^{30,31}$ However, in the analysis that excluded the 4 patients who took pioglitazone, a strong correlation remained between the change in abdominal fat distribution and $\triangle \mathrm{HDL}-\mathrm{C}$ in women. Second, all the participants in this study were non-obese, with an average BMI $( \pm \mathrm{SD})$ of $24.7 \pm 4.0$. Caucasians tend to be more obese and insulin resistant than East Asian populations. ${ }^{32,33}$ Therefore, studies of non-obese patients with T2DM may be more relevant to East Asian populations. Cross-sectional studies of apparently lean Japanese individuals demonstrated that a significant accumulation of VAT was associated with increased risk factors for cardiovascular disease and diabetes. These results were similar to what has been observed in obese patients with T2DM. ${ }^{23,34,35}$ Third, MRI abdomen is more accurate in 
Table 3 Spearman correlation coefficients between the change in abdominal fat distribution or WC and cardiovascular risk factors during the 6-month moderate low-carbohydrate diet

\begin{tabular}{|c|c|c|c|c|c|c|c|c|}
\hline & \multicolumn{8}{|l|}{$r$} \\
\hline & $\Delta$ VAT $\left(\mathrm{cm}^{2}\right)$ & $\Delta$ SAT $\left(\mathrm{cm}^{2}\right)$ & $\Delta$ TAT $\left(\mathrm{cm}^{2}\right)$ & $\% \Delta \mathbf{V A T}$ & $\% \Delta \mathbf{S A T}$ & $\% \Delta$ TAT & $\Delta \mathbf{V} / \mathbf{S}$ ratio & $\Delta W C(\mathrm{~cm})$ \\
\hline \multicolumn{9}{|l|}{$\operatorname{Men}(n=28)$} \\
\hline$\Delta$ Body mass index $\left(\mathrm{kg} / \mathrm{m}^{2}\right)$ & $0.533^{* *}$ & $0.747^{* *}$ & $0.735 * *$ & $0.656 * *$ & $0.707 * *$ & $0.742 * *$ & -0.173 & $0.678 * *$ \\
\hline $\begin{array}{l}\Delta \text { Standard deviation score } \\
\text { of body mass index }\end{array}$ & $0.544 * *$ & $0.729 * *$ & $0.73 I^{* *}$ & $0.662 * *$ & $0.697 * *$ & $0.743 * *$ & -0.150 & $0.667^{* *}$ \\
\hline$\Delta$ Systolic blood pressure $(\mathrm{mmHg})$ & 0.076 & 0.123 & 0.174 & 0.022 & 0.211 & 0.081 & -0.350 & 0.159 \\
\hline$\Delta$ Diastolic blood pressure $(\mathrm{mmHg})$ & 0.001 & 0.114 & 0.117 & 0.021 & 0.204 & 0.077 & -0.347 & 0.150 \\
\hline$\Delta$ Fasting blood glucose (mg/dL) & -0.083 & -0.125 & -0.138 & -0.094 & -0.088 & -0.096 & 0.021 & 0.140 \\
\hline$\Delta$ Fasting serum insulin $(\mu \mathrm{lU} / \mathrm{mL})$ & -0.236 & 0.070 & -0.137 & -0.075 & 0.123 & -0.042 & -0.292 & 0.119 \\
\hline$\Delta$ Hemoglobin $\mathrm{A}_{\mathrm{Ic}}(\%)$ & 0.210 & -0.041 & 0.115 & 0.050 & -0.080 & 0.028 & -0.006 & 0.055 \\
\hline$\Delta$ Triglyceride $(\mathrm{mg} / \mathrm{dL})$ & -0.110 & -0.173 & -0.173 & -0.004 & -0.128 & -0.089 & 0.228 & 0.176 \\
\hline$\Delta \mathrm{LDL}$-cholesterol (mg/dL) & 0.058 & 0.174 & 0.078 & -0.026 & 0.142 & -0.009 & -0.357 & 0.026 \\
\hline$\Delta \mathrm{HDL}$-cholesterol (mg/dL) & -0.166 & 0.075 & -0.119 & -0.243 & 0.085 & -0.213 & -0.268 & -0.005 \\
\hline \multicolumn{9}{|l|}{ Women $(n=24)$} \\
\hline$\Delta$ Body mass index $\left(\mathrm{kg} / \mathrm{m}^{2}\right)$ & 0.365 & 0.390 & $0.462^{*}$ & $0.596 * *$ & $0.448^{*}$ & $0.609 * *$ & -0.047 & $0.538 * *$ \\
\hline \multicolumn{9}{|l|}{ of body mass index } \\
\hline$\Delta$ Systolic blood pressure $(\mathrm{mmHg})$ & -0.037 & $-0.543 *$ & -0.292 & -0.081 & -0.455 & -0.275 & 0.240 & $-0.550 *$ \\
\hline$\Delta$ Diastolic blood pressure $(\mathrm{mmH})$ & -0.524 & -0.249 & -0.444 & -0.442 & -0.242 & -0.469 & -0.213 & -0.441 \\
\hline$\Delta$ Fasting blood glucose $(\mathrm{mg} / \mathrm{dL})$ & 0.282 & 0.381 & $0.533 * *$ & 0.283 & $0.417^{*}$ & $0.46 I^{*}$ & -0.110 & $0.444^{*}$ \\
\hline$\Delta$ Fasting serum insulin $(\mu \mathrm{lU} / \mathrm{mL})$ & 0.293 & -0.059 & 0.189 & 0.218 & -0.105 & 0.104 & 0.291 & 0.335 \\
\hline$\Delta$ Hemoglobin $\mathrm{A}_{\mathrm{Ic}}(\%)$ & 0.002 & -0.025 & 0.006 & 0.101 & 0.007 & 0.062 & 0.068 & 0.099 \\
\hline$\Delta$ Triglyceride (mg/dL) & 0.335 & -0.047 & 0.176 & $0.591 * *$ & 0.032 & 0.290 & 0.381 & 0.141 \\
\hline$\Delta \mathrm{LDL}$-cholesterol (mg/dL) & -0.007 & 0.143 & 0.129 & 0.070 & 0.151 & 0.168 & -0.030 & -0.036 \\
\hline$\Delta \mathrm{HDL}$-cholesterol (mg/dL) & 0.042 & $-0.699 * *$ & $-0.567 * *$ & -0.160 & $-0.720 * *$ & $-0.554 * *$ & $0.491 *$ & $-0.622 * *$ \\
\hline
\end{tabular}

Notes: $* P<0.05 ; * P<0.01$. Patients receiving lipid-lowering drugs were excluded from the analysis related to lipid profiles, as were patients receiving antihypertensive drugs from the analyses related to blood pressure.

Abbreviations: VAT, visceral adipose tissue; SAT, subcutaneous adipose tissue; TAT, total adipose tissue; V/S ratio, the ratio of visceral adipose tissue area to subcutaneous adipose tissue area; WC, waist circumference; HDL, high-density lipoprotein; LDL, low-density lipoprotein.

measurement of abdominal fat compared with CT, although it is more expensive. ${ }^{36}$

Finally, the lack of an HCD group as a control may be considered a limitation, although our study aimed to evaluate preferential abdominal fat loss induced by LCDs.

\section{Can preferential VAT loss be achieved with moderate LCDs?}

Most HCD intervention studies examining abdominal fat loss demonstrated absolute VAT and SAT loss in both sexes, as well as a reduction in weight. ${ }^{24-29,37,38}$ Our moderate LCD also significantly decreased absolute VAT and SAT and resulted in weight loss. These results agree with the results of an HCD intervention study involving non-obese Japanese patients with diabetes whose BMIs were similar to those of our patients. ${ }^{38}$ In terms of the percentage of abdominal fat loss, Chaston and Dixon reported that HCDs resulted in $8.3 \%-50 \%$ VAT loss and $2.6 \%-41 \%$ SAT loss in obese subjects with BMIs ranging from 26 to $40 .{ }^{18}$ Our moderate LCD also resulted in a $14.2 \%$ VAT loss in men and an
$18.9 \%$ VAT loss in women, as well as a $9.0 \%$ SAT loss in men and an $8.8 \%$ SAT loss in women. These results suggest that the efficacy of moderate LCDs on absolute changes, and on changes in the percentage of abdominal fat loss, is comparable to that of HCDs.

Regarding the preferential loss of VAT or SAT, many HCD intervention studies have reported equivocal and inconsistent results. These inconsistencies may be due to the variable intervention period, sex differences and the use of 2 methods ( $\%$ loss or ratio) to assess changes in VAT and SAT. Some studies were conducted for approximately 3 months in women only, ${ }^{24}$ and another was conducted for 4 weeks in men and women. ${ }^{19}$ Several studies used V/S to assess preferential abdominal fat loss, ${ }^{19,24,27,29,37}$ whereas another used the percentage of loss. ${ }^{18}$ The variety of study designs makes it difficult to compare results between studies. In addition, only a few of the HCD intervention studies used a 6-month study period or examined the sex difference..$^{25,37}$ Collectively, there is no compelling evidence of preferential VAT loss resulting from intervention with HCDs in either women or men. ${ }^{18}$ 
In contrast, our 6-month moderate LCD intervention study demonstrates that VAT and SAT significantly decreased in both sexes. Furthermore, $\% \Delta$ VAT was greater than $\% \Delta \mathrm{SAT}$ in men and women, but the difference did not achieve statistical significance in men. One possible reason for this discrepancy between men and women is that, compared with SAT loss, VAT loss may occur earlier in men. ${ }^{18} \mathrm{~A}$ study with an intermediate time point may have been able to detect the VAT loss, as well as a decrease in $\mathrm{HbA}_{1 \mathrm{c}}$ levels and BMI, in men. Earlier CT assessment of the changes in abdominal fat distribution may be warranted to evaluate preferential abdominal fat loss.

\section{The correlation between abdominal fat distribution and cardiovascular risk factors}

LCDs induce a decrease in FBG in conjunction with a decrease in serum TG levels and an increase in serum HDL-C levels, which are characteristic of the differences between LCDs and HCDs. ${ }^{1-5}$ This study demonstrates the correlations of changes in abdominal fat distribution with $\triangle \mathrm{FBG}$, $\Delta \mathrm{HDL}-\mathrm{C}$, and $\Delta \mathrm{TG}$ in women. Our results suggest that the major benefit of moderate LCDs is abdominal fat loss in patients with T2DM who have higher serum TG levels and/ or lower serum HDL-C levels.

Although numerous HCD intervention studies have been conducted, relatively little is known about the correlations between $\% \Delta$ VAT or $\% \Delta \mathrm{SAT}$ and changes in cardiovascular risk factors in patients on HCDs. One researcher has described correlations between $\Delta \mathrm{VAT}$ and $\Delta \mathrm{TG}$, as well as $\Delta \mathrm{V} / \mathrm{S}$ and $\Delta \mathrm{FBG} .{ }^{27}$ Others have described correlations between $\Delta \mathrm{VAT}$ and $\triangle \mathrm{FBG}, \Delta$ insulin and either $\Delta$ total cholesterol or $\Delta \mathrm{LDL}-\mathrm{C}$ and $\Delta$ SAT and either $\Delta$ total cholesterol or $\Delta$ LDL-C. ${ }^{28}$ The inconsistent results from the serum lipid profiles seem to be due to the high-carbohydrate conditions.

We focused on which adipose tissues contribute more to changes in cardiovascular risk factors. Concerning the above 3 cardiovascular risk factors, $\% \Delta \mathrm{SAT}$ was correlated with two $(\Delta \mathrm{FBG}$ and $\Delta \mathrm{HDL}-\mathrm{C})$ of the factors, while $\% \Delta \mathrm{VAT}$ was correlated with one $(\Delta \mathrm{TG})$. Taking into consideration the recent reviews that describe no compelling evidence of weight loss due to intervention with HCDs and/or exercise that targets preferential VAT loss, ${ }^{18}$ our study may provide evidence that SAT increases cardiovascular risk to the same extent as VAT in women.

\section{Conclusion}

A significant decrease in absolute VAT and SAT in men and women with good glycemic and BMI control, as well as a tapering off of sulfonylurea use and the improvement of the serum lipids profiles, can be achieved with the a moderate LCD. Significant preferential VAT loss was achieved in women, and VAT loss was greater than SAT loss in both men and women, although the difference was not statistically significant in men. Concomitantly, significant correlations of $\% \Delta$ SAT with $\Delta \mathrm{HDL}$, as well as $\Delta \mathrm{FBG}$ and $\% \Delta \mathrm{VAT}$ with $\Delta \mathrm{TG}$ were observed in women. We suggest that the moderate LCD may be effective for preferential VAT loss in patients with T2DM who have lower serum HDL-C and/or higher serum TG levels, and that both VAT and SAT may influence CRFs in female patients with T2DM who are following a moderate LCD.

However, we did not find a significant association between abdominal fat loss and changes in cardiovascular risk factors in men. Further detailed studies with intermediate assessments are required to clarify the relationship between preferential abdominal fat loss and changes in cardiovascular risk factors.

\section{Acknowledgments}

The authors would like to thank the nurses at Haimoto Clinic for their assistance and excellent patient care, and Mr Hideki Shibayama and Mr Yukiharu Watanabe for their technical support.

\section{Disclosure}

The authors declare that they have no competing interests.

\section{References}

1. Accurso A, Bernstein RK, Dahlqvist A, et al. Dietary carbohydrate restriction in type 2 diabetes mellitus and metabolic syndrome: time for a critical appraisal. Nutr Metab (Lond). 2008;5:9.

2. Volek JS, Fernandez ML, Feinman RD, Phinney SD. Dietary carbohydrate restriction induces a unique metabolic state positively affecting atherogenic dyslipidemia, fatty acid partitioning, and metabolic syndrome. Prog Lipid Res. 2008;47(5):307-318.

3. Hession M, Rolland C, Kulkarni U, Wise A, Broom J. Systematic review of randomized controlled trials of low-carbohydrate vs low-fat/ low-calorie diets in the management of obesity and its comorbidities. Obes Rev. 2009;10(1):36-50.

4. Katan MB. Alternatives to low-fat diets. Am J Clin Nutr. 2006;83(5): 989-990.

5. Foster GD, Wyatt HR, Hill JO, et al. Weight and metabolic outcomes after 2 years on a low-carbohydrate versus low-fat diet: a randomized trial. Ann Intern Med. 2010;153(3):147-157.

6. United States Department Of Agriculture ARS. What We Eat in America, National Health and Nutrition Examination Survey (NHANES), 2005 2006, individuals 2 years and over (excluding breast-fed children), Day 1 dietary intake data, weighted. 2008:1

7. Linseisen J, Welch AA, Ocke M, et al. Dietary fat intake in the European Prospective Investigation into Cancer and Nutrition: results from the 24-h dietary recalls. Eur J Clin Nutr. 2009;63(Suppl 4): S61-S80.

8. Cust AE, Skilton MR, van Bakel MM, et al. Total dietary carbohydrate, sugar, starch and fibre intakes in the European Prospective Investigation into Cancer and Nutrition. Eur J Clin Nutr. 2009 Nov;63(Suppl 4): S37-S60. 
9. Office fir Life-Style Related Diseases Control GAD, Health Service Bureau, Ministry Of Health, Labour and Welfare. The National Health Nutrition Survey, Japan: NHNS-J (2008). In: Health Service Bureau MOH, Labour and Welfare, ed, Tokyo; 2010:33-35.

10. Daly ME, Paisey R, Millward BA, et al. Short-term effects of severe dietary carbohydrate-restriction advice in Type 2 diabetes - a randomized controlled trial. Diabet Med. 2006;23(1):15-20.

11. Haimoto H, Iwata M, Wakai K, Umegaki H. Long-term effects of a diet loosely restricting carbohydrates on $\mathrm{HbA}_{1 \mathrm{c}}$ levels, BMI and tapering of sulfonylureas in type 2 diabetes: a 2-year follow-up study. Diabetes Res Clin Pract. 2008;79(2):350-356.

12. Haimoto H, Sasakabe T, Wakai K, Umegaki H. Effects of a lowcarbohydrate diet on glycemic control in outpatients with severe type 2 diabetes. Nutr Metab (Lond). 2009;6:21.

13. Johnston CS, Tjonn SL, Swan PD, White A, Hutchins H, Sears B. Ketogenic low-carbohydrate diets have no metabolic advantage over nonketogenic low-carbohydrate diets. Am J Clin Nutr. 2006;83(5): $1055-1061$.

14. Fox CS, Massaro JM, Hoffmann U, et al. Abdominal visceral and subcutaneous adipose tissue compartments: association with metabolic risk factors in the Framingham Heart Study. Circulation. 2007;116(1): 39-48.

15. Freedland ES. Role of a critical visceral adipose tissue threshold (CVATT) in metabolic syndrome: implications for controlling dietary carbohydrates: a review. Nutr Metab (Lond). 2004;1(1):12.

16. Wajchenberg BL. Subcutaneous and visceral adipose tissue: their relation to the metabolic syndrome. Endocr Rev. 2000;21(6):697-738.

17. Chrysohoou C, Panagiotakos DB, Pitsavos C, et al. Gender differences on the risk evaluation of acute coronary syndromes: the CARDIO2000 study. Prev Cardiol. 2003;6(2):71-77.

18. Chaston TB, Dixon JB. Factors associated with percent change in visceral versus subcutaneous abdominal fat during weight loss: findings from a systematic review. Int J Obes (Lond). 2008;32(4):619-628.

19. Miyashita Y, Koide N, Ohtsuka M, et al. Beneficial effect of low carbohydrate in low calorie diets on visceral fat reduction in type 2 diabetic patients with obesity. Diabetes Res Clin Pract. 2004;65(3): 235-241.

20. Sone H, Ito H, Ohashi Y, Akanuma Y, Yamada N. Obesity and type 2 diabetes in Japanese patients. Lancet. 2003;361(9351):85.

21. Hirose T, Kawamori R. Diabetes in Japan. Curr Diab Rep. 2005;5(3): 226-229.

22. Office fir Life-Style Related Diseases Control GAD, Health Service Bureau, Ministry Of Health, Labour and Welfare. The National Health Nutrition Survey, Japan: NHNS-J (2008). In: Health Service Bureau MOH, Labour and Welfare, ed, Tokyo; 2010:184-185.

23. Umegaki H, Haimoto H, Ishikawa J, Kario K. Visceral fat contribution of insulin resistance in elderly people. J Am Geriatr Soc. 2008;56(7): 1373-1375.

24. Okura T, Tanaka K, Nakanishi T, et al. Effects of obesity phenotype on coronary heart disease risk factors in response to weight loss. Obes Res. 2002;10(8):757-766.
25. Nicklas BJ, Dennis KE, Berman DM, Sorkin J, Ryan AS, Goldberg AP. Lifestyle intervention of hypocaloric dieting and walking reduces abdominal obesity and improves coronary heart disease risk factors in obese, postmenopausal, African-American and Caucasian women. J Gerontol A Biol Sci Med Sci. 2003;58(2):181-189.

26. Laaksonen DE, Kainulainen S, Rissanen A, Niskanen L. Relationships between changes in abdominal fat distribution and insulin sensitivity during a very low calorie diet in abdominally obese men and women. Nutr Metab Cardiovasc Dis. 2003;13(6):349-356.

27. Fujioka S, Matsuzawa Y, Tokunaga K, et al. Improvement of glucose and lipid metabolism associated with selective reduction of intraabdominal visceral fat in premenopausal women with visceral fat obesity. Int J Obes. 1991;15(12):853-859.

28. Janiszewski PM, Kuk JL, Ross R. Is the reduction of lower-body subcutaneous adipose tissue associated with elevations in risk factors for diabetes and cardiovascular disease? Diabetologia. 2008;51(8): 1475-1482.

29. Park HS, Sim SJ, Park JY. Effect of weight reduction on metabolic syndrome in Korean obese patients. J Korean Med Sci. 2004;19(2): 202-208.

30. Smith SR, De Jonge L, Volaufova J, Li Y, Xie H, Bray GA. Effect of pioglitazone on body composition and energy expenditure: a randomized controlled trial. Metabolism. 2005;54(1):24-32.

31. Hirose H, Kawai T, Yamamoto Y, et al. Effects of pioglitazone on metabolic parameters, body fat distribution, and serum adiponectin levels in Japanese male patients with type 2 diabetes. Metabolism. 2002;51(3):314-317.

32. Nakagami T, Qiao Q, Carstensen B, et al. Age, body mass index and Type 2 diabetes-associations modified by ethnicity. Diabetologia. 2003; 46(8):1063-1070.

33. Jensen CC, Cnop M, Hull RL, Fujimoto WY, Kahn SE. Beta-cell function is a major contributor to oral glucose tolerance in high-risk relatives of four ethnic groups in the US Diabetes. 2002;51(7):2170-2178.

34. Takami R, Takeda N, Hayashi M, et al. Body fatness and fat distribution as predictors of metabolic abnormalities and early carotid atherosclerosis. Diabetes Care. 2001;24(7):1248-1252.

35. Nagaretani H, Nakamura T, Funahashi T, et al. Visceral fat is a major contributor for multiple risk factor clustering in Japanese men with impaired glucose tolerance. Diabetes Care. 2001;24(12):2127-2133.

36. Silver HJ, Welch EB, Avison MJ, Niswender KD. Imaging body composition in obesity and weight loss: challenges and opportunities. Diabetes, Metabolic Syndrome and Obesity: Targets and Therapy. 2010;3:337-347.

37. Redman LM, Heilbronn LK, Martin CK, Alfonso A, Smith SR, Ravussin E. Effect of calorie restriction with or without exercise on body composition and fat distribution. J Clin Endocrinol Metab. 2007;92(3): 865-872.

38. Takami K, Takeda N, Nakashima K, et al. Effects of dietary treatment alone or diet with voglibose or glyburide on abdominal adipose tissue and metabolic abnormalities in patients with newly diagnosed type 2 diabetes. Diabetes Care. 2002;25(4):658-662.

\section{Publish your work in this journal}

Diabetes, Metabolic Syndrome and Obesity: Targets and Therapy is an international, peer-reviewed open-access journal committed to the rapid publication of the latest laboratory and clinical findings in the fields of diabetes, metabolic syndrome and obesity research. Original research, review, case reports, hypothesis formation, expert opinion and commentaries are all considered for publication. The manuscript management system is completely online and includes a very quick and fair peer-review system, which is all easy to use. Visit http://www.dovepress.com/testimonials.php to read real quotes from published authors. 